
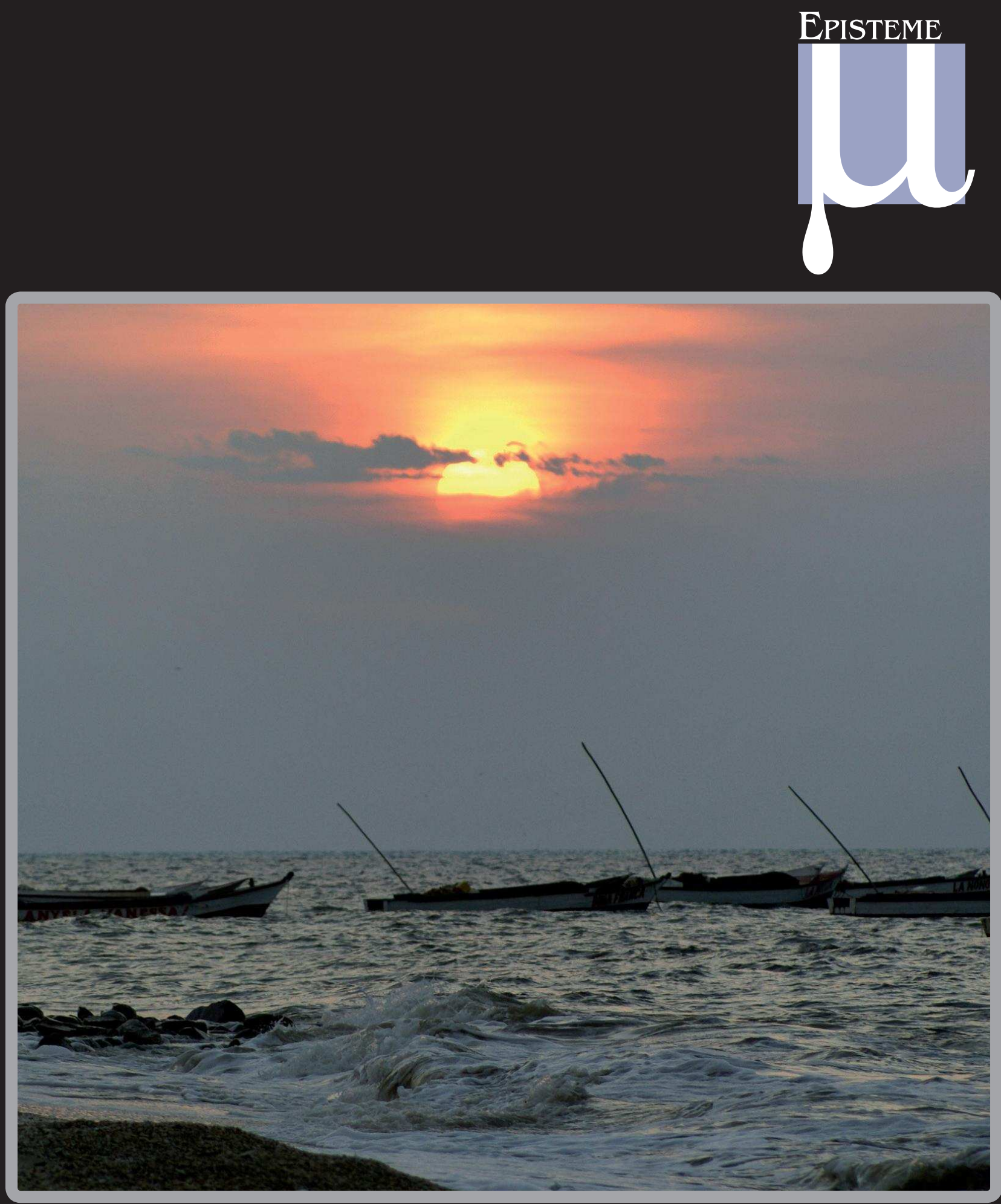

REFLEXIONES GENERALES SOBRE las Ciencias y el Conocimiento 


\title{
La naturaleza de la Matemática, sus concepciones y su influencia en el salón de clase.
}

\section{Mathematics Nature, Its Conceptions and Influence in the Classroom}

\author{
Alfonso Jiménez Espinosa ${ }^{1}$ \\ Escuela de Matemáticas y Estadística \\ Recepción: 07/08/2010 \\ Evaluación: $14 / 09 / 2010$ \\ Aceptación: 10/10/2010 \\ Articulo de investigación \\ Grupo de Investigación Pirámide. Universidad Pedagógica y Tecnológica de Colombia
}

\section{Resumen}

Aunque en las últimas dos décadas la situación tiende a cambiar, históricamente se ha tenido la creencia de que para enseñar matemáticas sólo se requiere el buen dominio de los temas, sin tener en cuenta que implícitamente hay una actitud frente a la clase; esta actitud del profesor se refleja en las actividades que desarrollan los estudiantes, de acuerdo con lo que él crea que es esta disciplina y con los fines que persiga su enseñanza; es decir, saber buena matemática es una condición necesaria, pero no suficiente para enseñarla. La actuación del profesor frente a sus estudiantes -la mayoría de las veces implícita e inconsciente- determina en gran medida el progreso de ellos, los resultados en sus aprendizajes y el gusto o la aversión por la matemática. Así las cosas, el problema no es solo cuánta matemática se sabe, ni cuál es la mejor forma de enseñarla, sino tener suficiente claridad sobre qué es realmente la matemática (Hersh, 1986).

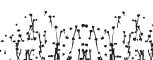

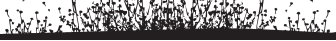

Alfonso Jiménez Espinosa,

Licenciado en Matemáticas

y Física Uptc. Doctorado

en Educación Matemática.

Universidad de Estadual de

Campinas

Maestría en Docencia

Universitaria. Universidad

Pedagógica Nacional

Especialización en Matemática avanzada Universidad

Nacional de Colombia.

Profesor de planta Lic. en

Matemáticas Universidad

Pedagógica y Tecnológica de

Colombia.

alfonso.jimenez@uptc.edu.co 
Tradicionalmente se han manejado dos formas básicas de concebir los conceptos matemáticos: como entes abstractos o como entes que tienen relación con el mundo y con el entorno en que se vive; a lo largo de la historia de la matemática, diversas escuelas filosóficas han estudiado estas dos formas de ver los objetos matemáticos, como el platonismo, el idealismo, el racionalismo, el logicismo, el empirismo, el constructivismo, el formalismo y, últimamente, el enfoque socio-cultural. De esta forma, el objetivo de este artículo es examinar algunas de estas posturas filosóficas sobre la naturaleza de la matemática, su incidencia en el salón de clase y en el aprendizaje de los estudiantes, y generar reflexión entre los docentes del área, conducente a hacer una matemática más agradable y significativa para los niños y jóvenes.

Palabras clave: naturaleza de la matemática, objeto matemático, enseñanza, aprendizaje.

\section{Abstract}

Even if in the last two decades the situation tends to change, the history of mathematical education shows that, it has had the belief that to be a maths teacher, one only needs a good command of its topics, without having in mind that one has an attitude in front of the class. The teacher's attitude is reflected in the activities that the students develop, according how he perceives the subject and the objectives pursued by his teachings. In other words, a good mathematics knowledge is a necessary condition, but not sufficient to teach it.

The teacher's performance in front of his students -most of the time implicit and unconscious- determines a great part of the students progress, the results in their learning and their like or dislike of the subject. Therefore, 'the problem is not only how much mathematics knowledge one has, nor which is the best way to teach it, but to have sufficient clarity of what mathematics is truly about' (Hersh, 1986).

Traditionally, there have been two basic forms of conceiving mathematical concepts: As abstract entities or as entities related to the world and the environment in which we live. Through the history of maths, diverse philosophical schools have studied these two forms of viewing mathematical notions: As abstract entities or entities which have a relation with the world and the environment where ones lives. Throughout maths' History diverse philosophical schools have studied these two ways to see the mathematical concepts, such as platonism, idealism, rationalism, logicism, empiricism, constructivism, formalism and ultimately the social-cultural approach. Thus the objective of this article is to examine some of these philosophical statements about mathematics nature, its presence in the classroom, and in the students learning in order to generate a reflection among those who teach it, to make mathematics more enjoyable and meaningful to children and teenagers.

Key words: Nature of Mathematics, Mathematical Object, Teaching, Learning. 


\section{Algunas concepciones}

Siempre ha sido materia de discusión qué se considera "un buen curso de matemáticas", y las explicaciones de quienes se dicen matemáticos se reducen, generalmente, a que el profesor sepa mucha matemática; pero saberla es una cosa, y enseñarla es otra. Nunca se hace el análisis desde la matemática misma (pues son verdades acabadas) y pocas veces desde lo que significa enseñarla, y casi nunca desde las dificultades y los fracasos de los alumnos. Sin embargo, hoy, ante los evidentes fracasos, reflexionar sobre dicha cuestión pareciera más actual que nunca. Aquí entran en juego varios factores, como qué se considera ser un buen profesor; las finalidades mismas del curso, de la enseñanza de la matemática y de la educación en general, y la relación con los contextos culturales, sociales y políticos. De hecho, la consideración anterior está en consonancia con preguntas como para quiénes enseñamos matemáticas y cómo se aprende matemáticas, pues dependiendo de las respuestas intentaremos enseñarla.

Para quienes se consideran "matemáticos puros", las explicaciones del fracaso solo se dan desde la responsabilidad y las capacidades del estudiante ('esto no es para todos', 'usted viene con malas bases'), y no se buscan otro tipo de explicaciones, como desde el interior de la propia matemática, y mucho menos desde el profesor, por su sapiencia... Una muy buena referencia de lo que suele suceder con las explicaciones del fracaso de los estudiantes en matemáticas la apunta Vasco:
Para los recién graduados de doctores en matemáticas ${ }^{2} \mathrm{o}$ en alguna de las ciencias naturales no hay sino un "dilema cruel" sobre los estudiantes que parecen no tener éxito en nuestra asignatura favorita. [...] los estudiantes que fracasan en nuestra asignatura favorita, o son perezosos o son brutos. Entre los dos cuernos de este dilema cruel no hay espacio para la pedagogía ni para la didáctica de las matemáticas o de las ciencias naturales (2008: 1).

Desde otras áreas, como la psicología, diversas escuelas han intentado responder, a su manera, por lo menos a la pregunta de cómo se aprende. En general, los estudios de varias escuelas psicológicas han discutido y reconocido la influencia del contexto del aprendiz en la construcción del conocimiento, frente a los enfoques analíticos y formalistas que lo hacen desde el contexto de justificación de la ciencia misma, aspectos que a pesar de su importancia no serán examinados aquí.

De otro lado, siempre se ha creído que la matemática se debe enseñar porque ayuda a estructurar el pensamiento y por su utilidad en cualquier campo de la ciencia o de la técnica y, aún más, en el diario vivir. Lo que en general no tiene muy claro la mayoría de los docentes es de qué manera sus concepciones sobre lo que es la matemática, sobre lo que es enseñar o sobre lo que es aprender pueden incidir en el logro de aprendizajes significativos en los estudiantes, y que apunten a los fines ya mencionados. De entrada, para analizar esta problemática debiera partirse de preguntas como ¿en últimas,

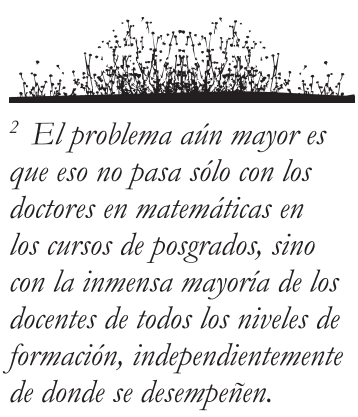

de donde se desempeñen. 
realmente qué es la matemática?, ¿cuáles son los objetos de la teoría matemática?, ¿con qué se hace matemática?, ¿cómo se hace matemática?, ¿cuál es la naturaleza y los fundamentos de esta ciencia?

La matemática, como cuerpo de conocimiento, a lo largo de la historia ha tenido un carácter multifacético, y la forma de concebirla no ha permanecido igual, ha sufrido un proceso de cambio y evolución constante en aspectos esenciales. En algunas de sus etapas se ha entendido como instrumento, en otras como sistema organizado o como lenguaje, axiomatización, deducción o formalización. Son estas formas de concebir el conocimiento matemático las que influyen directamente en la estructura de sus clases y en la postura del docente frente a sus estudiantes -la mayoría de las veces implícita e inconsciente-, que determina en gran medida el progreso de los estudiantes y el gusto o la aversión por la matemática; en síntesis, su concepción define todo; de acuerdo con la concepción que se tenga, hay una postura clara del profesor.

Para Stone (1978), el problema de las dificultades en el aprendizaje de las matemáticas se explica porque los cambios provocados en la ciencia han desbordado ampliamente la lenta evolución de los sistemas educativos. La dificultad parece radicar en que la repetición de una forma de hacer la docencia -justamente por creer que esa es la única forma de hacerla-, por la fuerza de la costumbre, hace muy difícil el cambio. Aquí cabe preguntarnos sobre quién más que los propios profesores de matemática podrían cambiar la situación; y la respuesta es solo una: nadie más que los propios profesores. Los cambios los podemos hacer sólo quienes nos dedicamos a enseñar matemáticas.

De cualquier forma, el profesor de matemáticas, si es que asume su papel como tal, debiera tener en cuenta lo que dice D'Amore: "El profesor de matemáticas no es un creador de teoremas ni de teorías, es un profesional experto en matemáticas a quien la sociedad le propone hacer sí que los jóvenes ciudadanos construyan y aprendan a usar competencias matemáticas" (2007: 8).

\section{Naturalezay génesis del conocimien- to matemático.}

Históricamente se han manejado dos formas básicas de dar respuesta a tales preguntas: desde el interior de la propia matemática y desde la actividad matemática en la experiencia, como parte integrante de la cultura. Es decir, hay una dualidad en la producción del saber matemático que se refiere: una explicación desde el interior de la propia disciplina y otra desde aspectos externos. En últimas, se discuten dos aspectos en el origen y desenvolvimiento de la matemática: el papel de la razón y el de la experiencia.

Respondiendo la pregunta de cuál es la naturaleza de los objetos matemáticos y, en últimas, qué estudia la matemática, Ponte et ál. (1997: 10) abordan la cuestión desde dos prismas de análisis: uno relacionado con la inmaterialidad de los objetos matemáticos y otro que busca ver esos objetos en su relación 
con el sujeto que los conoce o que busca conocerlos; es decir, los objetos matemáticos se pueden ver como entes abstractos o como entes que tienen relación con el mundo y el entorno en que se vive.

Tom aborda la situación desde el rigor, desde la pregunta: “¿cuál es la concepción del rigor matemático que debemos adoptar?" (1978: 120); para él hay tres respuestas posibles: la concepción formalista $^{3}$, la concepción realista o platónica ${ }^{4}$ y la concepción empirista o sociológica $^{5}$. La primera concepción no presenta las dificultades ontológicas (de origen) de la platónica, ni tiene el carácter arbitrario y vago (en la validez) de la empirista, así que él ve la primera como la más atrayente y que goza de mayor aceptación entre los matemáticos, aunque resulte insostenible, como lo demostró Gödel. A la incompletitud de la matemática -vista como un sistema formal-, que demostró Gödel, se le agrega que los matemáticos no están dispuestos a aceptar como válida una demostración hecha por un computador, pues dado el alto número de pasos o de cálculos, para un matemático resulta imposible la verificación.

Es indudable que quienes estén interesados en la educación matemática o, más específicamente, en que sus alumnos aprendan, deben conocer la evolución histórica de la naturaleza de las matemáticas. Stone (1978) considera que la naturaleza de las matemáticas ha sufrido una verdadera revolución, lo cual es innegable; sin embargo, no ha ocurrido lo mismo con la concepción que tienen los profesores de matemáticas, pues esta generalmente pasa del profesor al estudiante, en una reproducción inconsciente y reiterada. Para Stone, aunque ha habido cambios importantes en cuanto a la concepción de las matemáticas, "la única idea verdaderamente revolucionaria es el descubrimiento [sic] de que las matemáticas son totalmente independientes del mundo físico. [...] no se cree hoy día que las matemáticas tengan ninguna relación con el mundo físico..." (1978: 75). Aunque esta afirmación pueda ser válida entre los científicos en matemáticas -quienes producen matemática-, ¿podrá aceptarse por quienes enseñamos matemática en niveles de básica, media y pregrado? Si se piensa en las dificultades de los estudiantes, esa validez se diluye.

\section{Escuelas filosóficas del pensamiento matemático.}

Es bien conocida la imposibilidad de ofrecer una fundamentación sólida y definitiva de la matemática, a pesar de los intentos de distintas escuelas filosóficas. A lo largo de la historia ha habido varios momentos de crisis, generados por dudas acerca de criterios necesarios para fundamentar la matemática como ciencia. Según Snapper (1984), a pesar de constatarse desde el trabajo de Gödel un cierto desinterés entre los matemáticos contemporáneos en la fundamentación de la matemática, este asunto nunca ha sido abandonado. A continuación se mencionan aspectos destacados de algunas de esas escuelas de pensamiento, para buscar explicar la fundamentación de la matemática y para entender un poco su naturaleza.

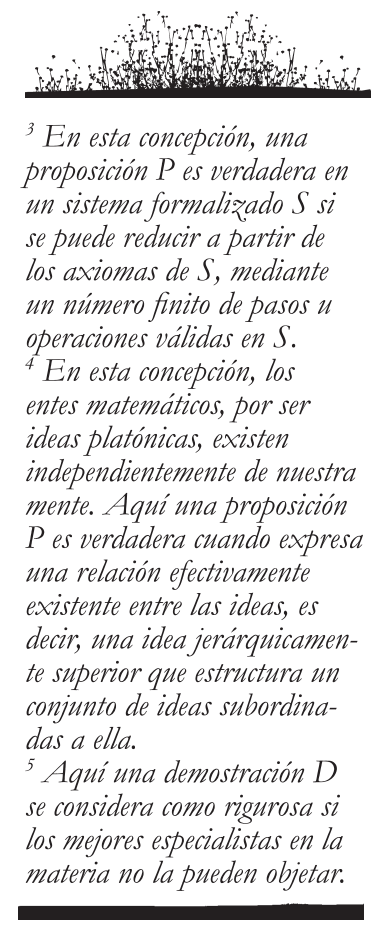


Platonismo - Idealismo - Realismo: La historia de la matemática en la civilizaciones más antiguas -matemáticas prehelénicas-, como la egipcia, la babilónica y la sumeria, muestra que los conceptos que en ella intervienen son objetos concretos, como enumeración de cosas, medidas (dimensiones) de objetos y operaciones que con esas enumeraciones o mediadas eran posibles. A decir de Schaaf, las matemáticas prehelénicas fueron empíricas, "eran intuitivas y poco elaboradas, y respondían fundamentalmente a exigencias prácticas" (1978: 62), mientras que las matemáticas de las civilizaciones orientales y semíticas "dejaron como herencia, al menos, una clarificación del papel de los símbolos y un sistema único de numeración" (1978: 62). Sin embargo, Platón, ante la necesidad de precisar nociones como figura, posición, tamaño, cantidad y medida, muestra que estas palabras "no designan nociones de la experiencia sensible, destacando que los matemáticos se sirven de figuras visibles para establecer raciocinios, pensando sin embargo no en ellas, sino en aquello con que se parecen" (Ponte, 1997: 11) o representan. Aristóteles, por su parte "[...] negaba que las matemáticas fueran una teoría de un conocimiento externo, independiente e inobservable; asociaba las matemáticas con una realidad donde el conocimiento se obtiene por experimentación, observación y abstracción" (Sánchez, 1993: 421); luego de la experimentación, la observación y la abstracción, se origina la inmaterialidad de los objetos matemáticos, como idealizaciones producidas por los matemáticos; para él, las matemáticas estudian objetos alcanzados por abstracción, de los que son eliminadas todas sus cualidades sensibles, como peso, tamaño o densidad. Más tarde, Euclides al usar el método axiomático-deductivo en sus demostraciones, no deja duda de la atribución a los objetos matemáticos como objetos de pensamiento.

De esta forma se constata que, en general, para la Escuela Platónica los objetos sobre los que se razona son entes completamente diferentes a los concretos, pero son obtenidos por abstracción a partir de objetos accesibles a los sentidos, de los que son solo imágenes. Sin embargo, según Ponte, hasta el siglo XVIII, a pesar de que los matemáticos reconocieran la inmaterialidad de los objetos matemáticos y el carácter ideal de esos entes, y de que tenían de ellos imágenes sensibles a los sentidos, para alcanzar nuevos progresos necesitaron introducir nuevos objetos matemáticos que dejaran de apoyarse en imágenes sensibles. Así comienza a configurarse la idea de que más importante que la naturaleza de esos objetos son las relaciones entre dichos objetos.

Variantes del platonismo son el idealismo y el racionalismo; los dos discuten la existencia de los objetos matemáticos desde el punto de vista de si son o no independientes del sujeto que los estudia. Para los idealistas, la realidad matemática está condicionada por las invenciones de los matemáticos, es decir, los objetos matemáticos son invenciones del espíritu humano; mientras que para los realistas la realidad matemática es un universo autónomo y los objetos matemáticos existen independientes del sujeto; es decir, para los realistas los objetos no se inventan, sino se descubren. Para los 
realistas, al igual que para Platón, los objetos matemáticos son reales, a pesar de que no sean objetos físicos y su existencia sea un hecho objetivo independiente de nuestro conocimiento. De esta forma, la matemática tiene una lógica interna y una existencia autónoma, existe fuera del espacio y del tiempo, es inmutable, no fue creada y, como tal, no cambiará. En síntesis, para los primeros matemáticos los objetos matemáticos se buscan en la realidad observable y experimental; para los idealistas se buscan en la actividad del individuo (inventándolos), y para los platonistas-realistas se buscan en un mundo atemporal (el mundo de las ideas), descubriéndolos. Para los platonistas, el mundo de las cosas es diferente del mundo de las ideas; el mundo de las cosas, o mundo material, contiene objetos y relaciones imperfectas, mientras que el de las ideas es un mundo donde se encuentran las verdades absolutas, inmutables, seguras e indestructibles.

Para Descartes, los conceptos matemáticos son entes "innatos" y "puestos por ahí por Dios"; al ser innatos son abstractos y tienen un carácter espiritualista, sin referencia al mundo físico. Sin embargo, la axiomática es un instrumento fundamental para la elaboración intelectual; esta axiomática se hace sobre verdades claras, únicas e innatas, por eso se dice que Descartes usó un reduccionismo axiomático (cfr. Ruiz, 1987). Leibniz, por su parte, eliminó radicalmente la intuición; según Köner, él decía: "Las proposiciones de la matemática son ciertas porque su negación sería lógicamente imposible" (En: Ruiz, 1987: 12). De esta forma,
Leibniz supera el intuicionismo de Descartes y le da una mayor fuerza a la axiomatización y una supervaloración a la Lógica, bases del paradigma axiomáticoformalista.

Racionalismo y Empirismo: Los racionalistas, al igual que Platón, ven la razón como un distintivo de la mente humana, a partir de la cual las verdades se pueden conocer, independientemente de la observación (experiencia). Entre los principales racionalistas se encuentran Descartes, Espinosa, Leibnitz y Kant. Para los racionalistas, la razón es la facultad que permite al ser humano entender cualquier cosa, cualidad observable especialmente en la matemática. Para los racionalistas, en últimas, esta ciencia "partía de verdades auto-evidentes, los axiomas, y a través de raciocinios establecidos por la razón conseguían descubrir y llegar a conclusiones no evidentes y a veces inesperadas" (Ponte, 1997: 16).

En el auge del racionalismo surge otra forma de ver y concebir el conocimiento: el empirismo, que afirmaba que el conocimiento proviene de la observación y de la experiencia, y que, como en todas las ciencias naturales, el conocimiento matemático es también producto de las generalizaciones inductivas hechas a partirdela experiencia y dela observación. Con esto los empiristas desafiaron la forma de hacer matemática y el valor y el papel de la razón en su constitución. Frente a esto, Kant distingue dos tipos de conocimiento, uno a priori y otro a posteriori. El conocimiento a priori es un conocimiento universal e intemporal, se fundamenta en la razón 
y es independiente de la experiencia; el mejor ejemplo de conocimiento a priori, según Kant, es el conocimiento matemático. El conocimiento a posteriori, o empírico, es un conjunto de proposiciones fundamentadas en la experiencia y en las observaciones del mundo físico. Para fundamentar la existencia del conocimiento a priori, Kant dice que el espíritu humano dispone de formas puras de espacio y de tiempo, o intuiciones, a través de las cuales se percibe, organiza y comprende la experiencia. A pesar que Kant glorifique la razón, no niega el valor de la experiencia; evidentemente fue Kant quien le dio a la matemática un estatus especial de organizadora del espíritu, una marca de validez intemporal e irrefutable, que aún conserva entre muchos profesores de matemáticas.

Regresando un poco al pasado, en un recorrido histórico, recordemos algunas crisis en el interior de la matemática. La primera surge con la aparición de las paradojas, como la de Zenón y la de la incomensuralidad de la diagonal con relación al lado de un cuadrado (aparecimiento de los irracionales), las cuales aclaran temporalmente la axiomatización y el trabajo de Euclides. Posteriormente, a finales del siglo XVIII, con el cuestionamiento del quinto postulado de Euclides y la aparición de las geometrías no euclídeas, aparece una nueva crisis, y para solucionarla se intenta quitar de la base de la matemática las nociones de los griegos y sustituirla por el concepto de número entero, época que se conoció con el nombre de la Aritmetización de la Matemática. Sin embargo, pronto aparece una nueva crisis con el aparecimiento de álgebras con propiedades, hasta entonces extrañas. Con esto se introducen operaciones diferentes a las de la aritmética con propiedades igualmente válidas; de esta forma empieza a dudarse de las verdades absolutas.

Logicismo: Escuela de pensamiento matemático y filosófico fundada por Frege y continuada por Peano, Russel y Whitehead; intenta buscar nuevos fundamentos para la matemática, que sustituyan los de la aritmetización, que no fueron suficientes. "El objetivo del logicismo era mostrar que la matemática clásica era parte de la lógica" (Snapper, 1984: 85). De esta forma, la pregunta de por qué la matemática clásica no contiene contradicciones, se transformó en por qué la lógica no contiene contradicciones. Este proyecto desarrolla la Teoría Formal de los Conjuntos en los Principia Mathematica e intenta mostrar que toda la matemática clásica puede reducirse a la lógica.

Zermelo y Fraenkel desarrollan otra teoría formal de los conjuntos, la cual tiene solo nueve axiomas. Así, los logicistas intentan mostrar que esos axiomas pertenecen a la lógica. El logicismo se basó en la tesis de que la matemática clásica puede ser definida como un conjunto de teoremas que pueden ser demostrados dentro de la lógica -la de Russel y Withehead o la Zermelo y Fraenkel-, entendiéndose aquella donde "una proposición lógica es una proposición que tiene generalidad completa y es verdadera en virtud de su forma, y no de su contenido" (Snapper: 
86). Hoy la lógica clásica podría definirse como constituida por todos aquellos teoremas que pueden ser demostrados en un lenguaje de primer orden.

A pesar del monumental avance de la matemática con el logicismo, a decir de Snapper, esa escuela no logra apartarse de inconsistencias, ya que dos de estos axiomas de la teoría de Zermelo y Fraenkel, el axioma del infinito y el axioma de elección, no pueden ser considerados proposiciones lógicas. Esto porque la aceptación de que son verdaderos se hace porque estamos familiarizados con muchos conjuntos infinitos, como el de los naturales o el de los puntos del espacio, o el de las estrellas, lo cual muestra que se aceptan en virtud de su contenido y no de su forma lógica, así que no son proposiciones lógicas en el sentido del logicismo.

Intuicionismo: $\mathrm{Al}$ contrario del logicismo, para el intuicionismo las entidades abstractas solo se admiten si hubiesen sido elaboradas por el hombre. Mientras los logicistas defendían que nada erróneo había en la matemática clásica e intentaron mostrar que esta era parte de la lógica, los intuicionistas creían que había muchos errores en ella. Con el desarrollo de la Teoría de Conjuntos de Georg Cantor y el aparecimiento de paradojas como la de Russel -debida a la libertad con que la desarrolló y por no ser axiomática-, los intuicionistas consideran que esas paradojas son claras indicaciones de que la matemática clásica está lejos de ser perfecta. Creían los intuicionistas que "la matemática debería ser reconstruida a partir de sus orígenes, y, según su filosofía, esos orígenes eran básicamente la explicación que daban a los números naturales y la idea de que todos los seres humanos tienen dentro de sí una intuición primordial de los números naturales" (Snapper, 1984: 88). En síntesis, para el intuicionismo la matemática es la actividad mental que consiste en efectuar un constructo después de otro, en un encadenamiento. Por esto al intuicionismo también se le llama constructivismo. A decir de este autor, a pesar de que dentro de la teoría intuicionista no se encuentren contradicciones, al examinar de fuera, desde el punto de vista del matemático clásico, se tiene que confesar que el intuicionismo no consiguió dar fundamentos adecuados a la matemática.

Formalismo: Escuela creada por David Hilbert a comienzo del siglo xx; tuvo como objetivo "encontrar una técnica matemática por medio de la cual se pudiese demostrar, de una vez por todas, que la matemática estaba libre de contradicciones" (Ponte et ál. 1997: 27). El formalismo comienza planteándose la pregunta de ¿qué es lo que en últimas se formaliza al formalizar alguna cosa? Y la respuesta es que lo que se formaliza es una teoría axiomatizada dada. "Euclides axiomatizó la geometría hacia el año 1300 a.C., pero su formalización comenzó solamente 2200 más tarde con los logicistas y formalistas" (Snapper: 91). Para cumplir con su objetivo los formalistas introdujeron un lenguaje formal y reglas de inferencia suficientes, unas propiedades combinatorias de este lenguaje formal, y con esto se propusieron demostrar que dentro de 
este sistema no se podían presentar contradicciones. Para el formalista estricto, "hacer matemática es manipular los símbolos sin sentido de un lenguaje de primer orden, según reglas sintácticas explícitas. Así el formalista no trabaja con entidades abstractas, como series infinitas o números cardinales, sino solamente con sus nombres sin sentido que son las expresiones de un lenguaje de primer orden" (Snapper: 93).

Según Snapper, los formalistas no pudieron llegar a completar con éxito su programa, pues en 1931 Kurt Göedel demostró que la formalización no se puede considerar una técnica matemática por medio de la cual sea posible probar que la matemática está exenta de contradicciones.

\section{Implicaciones de las concepciones en el aula de clase.}

Ya se mencionó que la concepción que se tenga sobre lo que se crea que sea la matemática tiene consecuencias directas, a veces dramáticas, en el accionar del profesor en su clase; sobre este tema, René Thom afirma: "En verdad, quiérase esto o no, toda pedagogía de la matemática, incluso poco coherente, se basa en una filosofía de la matemática" (en Steiner, 1987). Tales filosofías -más creencias que otra cosa- pueden tratarse solo de una opinión individual de un profesor sobre la naturaleza de la matemática y del conocimiento matemático - frecuentemente "heredada" indirectamente de sus profesores en sus estudios académicos- y de sus reflexiones sobre la forma como esa opinión se relaciona con su enseñanza y con el aprendizaje de sus alumnos. Como ejemplo se cita a Steiner (1987) sobre las críticas al movimiento de la Matemática Moderna en la educación básica y media, para quien su fracaso se debe justamente a la filosofía que la fundamentaba, con una orientación "mental unilateral" basada en la hipótesis de la naturaleza humana universal, coherente, homogénea e ideal, tanto de las estructuras matemáticas como de la mente humana.

Una consecuencia de lo anterior es la introducción de una rigurosa simbolización muy temprana en el desarrollo de los cursos, la cual es perjudicial si no se hace gradual, como resultado de abstracciones; "es necesario proceder desde el principio de un modo disciplinado y sistemático, sin que eso nos lleve a abstracciones que los alumnos sean incapaces de entender. La precisión y la claridad no excluyen las representaciones gráficas, y el trabajo sistemático no debe degenerar en una pedantería dogmática" (Nevanlinna, 1978: 110). En el mismo sentido se manifiesta Dieudonné al referirse a la axiomatización desmedida que se da en ciertos cursos universitarios, y afirma que está de acuerdo con Thom en:

su crítica de la nefasta tendencia de muchos jóvenes profesores universitarios a introducir demasiado pronto dosis excesivas de álgebra abstracta sin que sea en absoluto necesario. Numerosos matemáticos, y en particular Kronecker y Chevalley, dos de los más grandes algebristas de todos los tiempos, han recordado con frecuencia que el álgebra, 
aunque sea muy útil por sí misma, no debe hacerse jamás sin una motivación procedente de otra parte de las matemáticas; es decir, que el álgebra debe limitarse a desarrollar las herramientas que necesitan las demás ramas de las matemáticas para la resolución de sus problemas particulares. De no ser así, llegaremos a lo que Thom llama "desarrollos formales de teorías insignificantes y carentes de interés" (1978: página ).

Otros fracasos se asocian con la visión purista o estática de la matemática, que desconoce las aplicaciones de la teoría matemática y de los conceptos tal como ellos se presentan en el mundo físico y que olvida también la dimensión representacional y social de la matemática. A este respecto Nevanlinna afirma:

No debemos olvidar que la principal razón de ser de la investigación matemática ha sido, durante los periodos más vivos y florecientes, el sentimiento (y la creencia), un poco vagos si se quiere, de que las matemáticas no han perdido, ni aun en sus especulaciones teóricas más elevadas, el contacto con la "realidad empírica", y que esto les confiere una posición preeminente dentro de la variedad y unidad de la cultura considerada como un todo (1978: 107).

Lo anterior nos lleva a otro punto, a considerar la artificial separación entre matemática pura y matemática aplicada, solo por creer que juna da más estatus que otra! Los grandes matemáticos siempre hicieron inmensos aportes a las aplicaciones, incluso los últimos más destacados, como Klein, Hilbert, Poincaré y Minkouwski, entre otros. Para Nevanlinna, la explicación que se suele dar a tal división, de que es una consecuencia del desarrollo cada vez mayor de la ciencia, resulta insuficiente. Poveda destaca el profundo daño que le causa al desarrollo del país la separación artificial entre Matemática Pura y Matemática Aplicada: "esa dicotomía contribuye eficazmente a afianzar y a prolongar la esterilidad de la ciencia y la tecnología en nuestro propio suelo, $y$, por lo tanto, a prolongar las condiciones de dependencia tecnológica y científica del país" (1986: 109). Y agrega que en Colombia la separación es perjudicial por cuanto ha negado a las demás ciencias mucho del posible efecto impulsor que les puede dar la matemática: "A los matemáticos que hoy formamos en el afán vigente del purismo se les veda su acceso a todas estas posibilidades", y continúa: "Mientras estemos formando matemáticos únicamente para que enseñen ${ }^{6}$ matemática a los de la generación que vendrá, estaremos reconstruyendo la divertida y gráfica anécdota vietnamita del cazador de dragones" (Poveda: 110). Si bien esta aseveración puede resultar temeraria, realmente no lo es, pues para los niveles escolares donde el estudiante aún no ha logrado un pensamiento totalmente analítico, esa separación y esa postura, en la práctica, resultan catastróficas.

Actuando en provecho del aprendizaje se desaconseja esa separación entre Matemática Pura y Matemática Aplicada, pues forma parte de la naturaleza humana el que la comprensión tenga lugar yendo de lo concreto a lo abstracto,

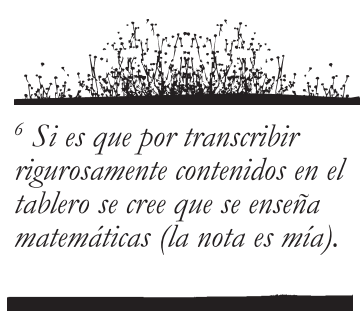


de lo particular a lo general, y entonces esto sugiere que la enseñanza parta de situaciones que se conocen de antemano o que al menos sean más fáciles de comprender por los alumnos. Cabe aquí mencionar los casos de niños, sobre todo de estratos bajos, que antes de ir a la escuela hacen estimaciones y cálculos con gran agilidad y precisión, pero que al llegar a la escuela, al ser obligados a seguir algoritmos tediosos o a resolver problemas descontextualizados y sin sentido para ellos, fracasan dramáticamente. De esta forma la clase de matemáticas exige mucho más de los profesores que de los alumnos, y creo que ahí se explica gran parte del fracaso escolar en matemáticas, y no solo en los niveles básicos, sino también en el superior e incluso en los niveles más avanzados.

En investigaciones sobre el pensamiento del profesor, Alba Thompson concluye que el fuerte énfasis que pone el profesor en el rigor -como muchos profesores piensan que debe ser, y que es eso exclusivamente lo que deben hacer-, la precisión y la deducción en matemáticas torna para ellos mismos difícil justificar y realizar enfoques genéticos (Piaget), orientar la enseñanza hacia la resolución de problemas o de la modelación, enfoques estos que exigen una visión de la matemática como un campo abierto, flexible y en permanente desenvolvimiento, más que aquel campo cerrado, fijo, listo y acabado.

Sobre la concepción platónica de la matemática y la incidencia que tiene en la postura del profesor y en su clase, Bkouche et ál. manifiestan que en la enseñanza clásica de la matemática basada en una epistemología y ontología platónicas, las ideas matemáticas tienen es sí mismas una realidad. En esta concepción una vez desvendada la verdad matemática se da a quien la sabe ver, a quien tiene el poder de abstracción suficiente. El papel del profesor es llevar al alumno a que comparta esa misma visión a la que el profesor ya tuvo acceso, a dirigir el espíritu del alumno - la mirada del alma, como decía Platón- al mundo matemático $[\ldots]$ Desde luego que lo que el profesor retiene de la actividad del matemático no esa actividad, que la mayor parte de las veces ignora y sobre las cuales guarda silencio e intenta repetir sus resultados en forma de axiomas, definiciones, teoremas y demostraciones. El profesor sobrevalora esa forma, los resultados, los cuales solos no tienen sentido, y esto resulta paradójico, ya que a esos resultados el matemático llegó de forma caótica y fueron condensados a posteriori. Esa ruptura entre la actividad matemática y los resultados [los conceptos abstractos], entre los problemas y los conceptos, originan el fracaso escolar... (en Ponte et ál. 1997: 14).

Tanto un docente con pensamiento platónico -los entes matemáticos existen independientemente del sujeto-, como otro centrado en el Positivismo Lógico (Formalismo) -la matemática se reduce a un lenguaje, a su sintaxis y semántica generales-, justifican su trabajo en la simple trasmisión de las verdades al alumno en su lenguaje, el de la axiomatización, sin preocuparse por las ideas espontáneas de sus alumnos y la relación que pueda haber de los conceptos con su entorno (Cfr. Piaget, 1978: 219). Si el docente tuviera en cuenta justamente aquello por lo que no se preocupa, podría favorecer en sus alumnos la aparición de vocaciones 
creadoras, en vez de convertirlos en meros recipientes conformistas y pasivos. Pero tener en cuenta las ideas espontáneas de los alumnos y la relación de los conceptos con su entorno y experiencia, es decir, las constataciones empíricas, no significa de ninguna manera renunciar a que la clase de matemáticas tenga una exigencia básica de una educación matemática dentro de un espíritu deductivo y formal.

Para el mismo Piaget, la dificultad por resolver es "el ser capaz de injertar las nociones generales, que el maestro sólo concibe en su propio lenguaje, en los casos particulares de esas nociones que los alumnos construyen y utilizan" (1978: 225). Lo anterior determina tener en cuenta el principio del aprendizaje, que la comprensión real de una noción supone su reinvención por el aprendiz. Esto, según Piaget, supone que el sujeto haya sido capaz de encontrar por sí mismo las razones de la verdad que intenta comprender.

Cuando se concibe la matemática como un cuerpo acabado de verdades absolutas o como un lenguaje formal, se tiene que seguir el libro de texto como un instrumento imprescindible. Aquí las clases de matemáticas se reducen a la explicación del texto a los estudiantes, al pie de la letra. La inconveniencia de esta forma de hacer la clase radica en que el libro nunca muestra las dificultades y los procesos en el desarrollo de los conceptos, y justamente por eso los conceptos matemáticos se perciben como verdades que deben ser consumidas, grabadas. De esta forma, el libro de texto y el profesor se convierten en las autoridades absolutas para el estudiante, y solo ellos determinan cuándo un resultado o un problema son correctos. De ahí la prepotencia de algunos profesores que trasmiten esa misma convicción al estudiante, quien, obviamente, reproducirá la misma creencia y actitud.

Bajo la influencia del filósofo Popper y de varios matemáticos, como Lakatos y Ernest, entre otros, se quieren comprender los procesos de producción del saber científico y las prácticas reales de los científicos, en la búsqueda de una nueva filosofía y epistemología. Desde allí se propone un nuevo enfoque para la filosofía de la matemática, designado con el nombre de casi-empirismo, que procura caracterizar y describir la matemática a partir del análisis de las prácticas reales de los matemáticos y del papel de la experiencia, del origen e historia en los contextos sociales de producción del conocimiento matemático. Este enfoque destaca que la matemática constituye una actividad humana, simultáneamente individual y social, que es producto del diálogo entre quienes intentan resolver un problema.

Sobre la enseñanza de la matemática bajo una perspectiva social, con enfoque casi-empírico, Ernest destaca que "este enfoque da soporte a abordajes pedagógicos basados en la formulación y resolución de problemas, semejantes a los procesos por los que se generó el conocimiento matemático. Este enfoque tiene incidencia en objetivos que buscan formar personas capaces de problematizar los usos sociales de la matemática" (en Ponte 1997: 34). 
Para finalizar, conviene reflexionar sobre interrogantes como ¿no será que las concepciones rígidas platónicas y formalistas de los profesores son la razón más fuerte del rechazo social generalizado hacia la matemática?; al respecto vale anotar que en el caso de un formalismo excesivo, sólo como un juego lingüístico, donde se manejan símbolos con reglas sintácticas, todo puede terminar con muy poco o ningún sentido. $\mathrm{Y}$ ¿no será esta última una de las razones por las que los estudiantes se "aprenden" de memoria las demostraciones, que olvidan pasada la evaluación?: pues es claro que deben "memorizar" la demostración, dado que no ha habido un proceso de matematización y construcción de los conceptos. Estos son aspectos sobre los que todo profesor de matemática debe reflexionar para intentar cambiar tanta creencia errónea sobre la disciplina y tanto fracaso escolar.

La alta calidad de la educación matemática, en últimas, no depende de seguir tales o cuales lineamientos o de que se deben desarrollar tales o cuales competencias, ni de seguir algoritmos o de memorizar demostraciones; se trata de una sola cosa: de que el alumno aprenda a pensar matemáticamente, que aprenda a matematizar ${ }^{7}$. Como docentes, la tarea es estudiar, reflexionar y actuar para cambiar la situación, pues como dice Nevanlinna: "Puede enseñarse bien de varias maneras, puede hacerse mal de muchísimas, pero lo peor de todo es hacerlo de un modo aburrido. El resultado de la enseñanza de las matemáticas depende en gran medida de la capacidad pedagógica de sus profesores" (1978: 114). 


\section{Bibliografía}

D’Amore, Bruno. (2007): El papel de la epistemología en la formación de profesores de matemática de la escuela secundaria. Bogotá: Universidad Nacional de Colombia, Instituto de Investigación en Educación, Facultad de Ciencias Humanas. Colección Cuadernos del Seminario en Educación.

D’Amore, Bruno, Radford, Luis, y Babni, Giorgio. (2007): Obstáculos epistemológicos y perspectiva socio-cultural de la matemática. Bogotá: Universidad Nacional de Colombia, Instituto de Investigación en Educación, Facultad de Ciencias Humanas. Colección Cuadernos del Seminario en Educación.

DieudonNé, Jean. (1978): “¿Debemos enseñar las matemáticas modernas?”. En: Piaget, J.; Choquet, G.; Dieudonné, J.; Thom, T. y otros: La enseñanza de las matemáticas modernas. Madrid: Alianza Editorial.

Dou, Alberto. (1970): Fundamentos de la matemática. Barcelona: Editorial Labor.

HemPel, Carl.; Wilder, Raymond.; Napel, Ernest.; Newman, James.; Veblen, John. y otros. (1974): Matemática, verdad, realidad. Barcelona: Grijalbo.

Hersh, R. (1986): "Some proposals' for reviving the philosophy of mathematics". In: T. Tymoczko (Org.): New directions in the philosophy of mathematics, pp. 9-289. Boston: Birkhäuser.

Nevanlinna, Rolf. (1978): "La reforma de la enseñanza de las matemáticas". En: Piaget, J.; Choquet, G.; Dieudonné, J.; Thom, T. y otros: La enseñanza de las matemáticas modernas. Madrid: Alianza Editorial.

Piaget, Jean. (1978): "Observaciones sobre la educación matemática". En: Piaget, J.; Choquet, G.; Dieudonné, J.; Thom, T. y otros: La enseñanza de las matemáticas modernas. Madrid: Alianza Editorial.

Ponte, João Pedro Da.; Boavida, Ana María; Graça, Margarida e Abrantes, Paulo (1997): Didáctica da Matemática: Matemática - ensino secundário. Lisboa: Ministério da Educação de Portugal.

Poveda R, Gabriel. (1986): "El falso dilema de la matemática pura y la matemática aplicada". Revista Ciencia, Tecnología y Desarrollo; 10 (1-2): 99-111; enerojunio, 1986. Bogotá.

Ruiz Z., Ángel. (1987): "Algunas implicaciones de la filosofía y la historia de las matemáticas en su enseñanza". Revista Educación; 11(1): 7-19. México.

SÁnchez T., Manuel. (1993): "La naturaleza de las matemáticas y sus implicaciones didácticas". Mathesis, 9: 19-142.

SCHAAF, William. (1978): "Sobre la modernidad de las matemáticas modernas". En: Piaget, J.; Choquet, G.; Dieudonné, J.; Thom, T. y otros: La enseñanza de las matemáticas modernas. Madrid: Alianza Editorial. 
SNAPPER, Ernest. (1984): "As três crises da matemática: o logicismo, o intuicionismo, e o formalismo". Revista Humanidades, julho- setembro, 1984, II(8): 85-93. Universidade de Brasilia.

STEINER, Hans-Georg. (1987): “Aspectos filosóficos e epistemológicos da matemática e suas interações com a teoria e a prática em educação matemática”. In: For the Learning of Mathematics 7, february 1987. Tradução ao português de Antonio Miguel, Universidade Estadual de Campinas - FE/CEMPEM, Brasil [documento de circulação restrito].

STONE, Marshall. (1978): "La revolución en las matemáticas". En: Piaget, J.; Choquet, G.; Dieudonné, J.; Thom, T. y otros: La enseñanza de las matemáticas modernas. Madrid: Alianza Editorial.

Thompson, A. (1992): "Teachers belief and conceptions: a synthesis of the research". In: GROWUS, D. (org.): Handbook of research on mathematics teaching and learning, pp. 127-146. Nova York, NCTM, MacMillan.

VAsco, Carlos. (2008): Palabras de agradecimiento por el Premio "Fransiska Radke". Bogotá, 30 de julio de 2008. 